\title{
Entre o técnico, o político e o social: impasses e poderes de uma política habitacional - PAC Barnabé
}

\author{
Between the technical, political and social: deadlocks and power of a \\ housing policy - PAC Barnabé \\ http://dx.doi.org/10.5007/2178-4582.2016v50n1p185
}

Débora Allebrandt

Universidade Federal de Alagoas, Maceió/AL, Brasil

Tânia Moreira Felix

Associação riograndense de empreendimentos de assistência técnica e extensão rural - EMATER, Porto Alegre/RS, Brasil

Inúmeros são os desafios ligados à aplicação prática do que fora aprendido em salas de aula por muitos profissionais. Cada vez mais, sociólogos e antropólogos têm deixado o privilegiado espaço de reflexão e crítica das universidades para adentrarem num terreno minado - o das políticas públicas. A partir da experiência vivida pelas autoras como consultora e coordenadora da equipe de trabalho social do Projeto de Revitalização do Arroio Barnabé (PAC Barnabé), buscamos dar ênfase a alguns aspectos ligados diretamente a esse "novo" encontro. Esse artigo situa nossa experiência na execução do PAC enquanto parte da equipe de trabalho social e da emblemática relação com a equipe do projeto arquitetônico. Nosso objetivo é problematizar o lugar para o qual cientistas sociais, e especialmente os antropólogos, são chamados a ocupar enquanto executores de políticas públicas.

Palavras-chave: PAC; Arroio Barnabé; Políticas Públicas; Antropologia Aplicada
There are countless challenges related to practical application of what is learned in the classrooms by many professionals. Increasingly, sociologists and anthropologists leave the privileged space for reflection and criticism of universities to step into a minefield of powers- that of public policy. From the experience lived by the authors as a consultant and coordinator of the social work team of the Revitalization Project of the Barnabe stream (PAC Barnabé) we seek to emphasize some aspects linked directly to this "new" meeting. The Growth Acceleration Program (PAC) of the Federal Government funded this project. In this article we place our experience in the execution of PAC Barnabe in reference to the construction of a social intervention team and the relationship and mediation between the execution of both social and architectural projects. Our goal is to discuss the place for which anthropologists are called to occupy as public policy executors.

Keywords: PAC; Barnabé stream; Public Policy; Applied Anthropology

\section{O PAC Barnabé}

Em nosso primeiro contato com o PAC Barnabé, fomos apresentadas a uma audaciosa proposta: o Governo Federal havia confiado à prefeitura da

\footnotetext{
1 As autoras agradecem os pareceristas dessa edição por seus valiosos comentários. Aproveitamos essa ocasião para agradecer a leitura primorosa das colegas Heloísa Helena Salvatti Paim e Lucia Mury Scalco que muito ajudar a partilhar reflexões e inquietações sobre nossa atuação fora da academia.
} 

de...

cidade de Gravataí a responsabilidade de executar um projeto de desenvolvimento urbano e transformar qualitativamente a vida de 496 famílias em apenas 12 meses (fevereiro de 2008 à janeiro de 2009). Se, em números brutos, tal tarefa soa homérica, na prática, outros obstáculos faziam dessa tarefa uma “missão". No início de 2008 o PAC já era uma plataforma de governo bastante conhecida, sobretudo por grandes obras como barragens, transposição de rios, construções de estradas entre outras. Esse programa ainda era pouco relacionado a ações habitacionais como a proposta do PAC Barnabé.

Fomos incorporadas à "equipe social” três meses após o início da implementação do projeto e nossa participação no PAC Barnabé foi um exercício constante de "correr atrás do prejuízo". Sem projeto de intervenção ou estudo prévio $^{2}$ sobre a comunidade abrangida, nossa chegada ao PAC Barnabé se deu em meio a um universo complexo e heterogêneo de obras e remoções, cujo ponto de unificação eram as 496 unidades habitacionais para 496 famílias (ainda sem nome). Nesses curtos 12 meses, a equipe se deparou com o infortúnio de uma eleição e verá o projeto social sendo colocado em prática de acordo com poderes e redes que ultrapassam domínios locais. Nesse contexto, as pesquisadoras questionaram seu ambíguo papel nas tensões cotidianas e problematizaram o peso de sua formação durante a tomada de decisões. A concretização desse projeto incita um primeiro evento de intervenção massiva do Estado, e sucessivamente, uma oportunidade de evidenciar demandas há muito tempo silenciadas.

É importante salientar que este artigo é fruto de uma reflexão acerca de nossa experiência de trabalho como consultora e coordenadora da equipe social do PAC-Barnabé. Nosso intuito foi problematizar, a partir dessa experiência, a delicada relação dos antropólogos e cientistas sociais na mediação da aplicação de políticas públicas. Apesar de nos identificarmos com o método etnográfico, esta não é uma etnografia, e as descrições do Barnabé e seus residentes, bem como de nossos colegas de trabalho, são contextualizações que buscam melhor situar o leitor nesse complexo universo. Pela amplitude do projeto, pela grande circulação de pessoas nos postos de trabalho, e pelo tempo transcorrido desde sua execução (2008), acreditamos que as pessoas aqui citadas com pseudônimos não podem ser identificadas.

Elencando as dificuldades que se apresentaram durante o trabalho, faremos referência a algumas situações que foram recorrentes e podem nos dar pistas sobre o lugar do antropólogo e cientista social na aplicação de políticas

2 Para a solicitação do financiamento, a Secretaria Municipal de Captação de Recursos (SMCR) contratou um estudo com objetivo de delinear o número e o perfil socioeconômico da comunidade a ser abrangida pelo projeto. No entanto, esse estudo demonstrou-se equivocado em inúmeros aspectos, sendo o mais evidente a extensão do número de famílias abrangidas. 
públicas. São elas: a preocupação com a fraude e a constatação da ingratidão; a negociação de prioridades e necessidades para a obra e para a comunidade; e a oposição entre o trabalho "técnico" e "social". Para fins de organização, iniciaremos descrevendo Barnabé e seus moradores, passaremos para uma breve contextualização do projeto de desenvolvimento do PAC Barnabé e situaremos a equipe social e desafios de sua atividade. Para finalizar, discutiremos a relação do projeto social e arquitetônico na prática da implementação dessa política pública.

\section{O Barnabé e seus moradores}

Gravataí é uma das cidades que compõem a área metropolitana de Porto Alegre. Como é comum em áreas metropolitanas, as cidades que envolvem a capital podem se desenvolver como cidades dormitórios, pois parte de seus moradores precisam se deslocar até a capital em busca de trabalho e outras fontes de renda. Gravataí não foge a essa regra, apesar de ter alocado uma grande montadora de automóveis nos anos 2000, com a expectativa do crescimento econômico que uma empresa desse porte poderia trazer. Levando o nome do rio que a banha, a cidade está situada sobre uma importante bacia hidrográfica, da qual faz parte o arroio Barnabé. A ocupação irregular das margens do arroio vem de longa data. Embora não exista uma historiografia oficial da região, a partir dos relatos dos moradores mais antigos, o início da urbanização do Arroio Barnabé ocorreu entre os anos de 1930 e 1950.

Memorado pelos anciões como verde e vazio, no início da intervenção do PAC, o arroio havia sido esquecido e se tornado um grande depósito de lixo, conhecido como "valão". Coexistiam nesse ambiente antigas casas de alvenaria e casas de madeira e outros materiais que lhes davam como característica a fragilidade e a improvisação. Essas moradias sofriam com as chuvas, que elevavam rapidamente o nível do arroio e alagavam casas, quando não as arrastavam com sua força.

O longo processo de ocupação das margens do Barnabé não pode ser visualizado em camadas de estratificação de moradores mais antigos e mais novos como podemos ver em trabalhos como os de Fonseca (2005), no qual moradores mais antigos, residem mais próximos da "avenida", e moradores mais novos, no alto do morro. O que estamos chamando de "Barnabé" é uma favela horizontal que se estende ao longo das margens do arroio. O que impera nesse local é a mistura de casas mais antigas e novas sem uma separação geográfica que demarque também um status diferenciado. As casas, em sua maioria, compostas de diferentes materiais e fontes estão sempre em construção ou reconstrução. Nelas, todos os dias são incorporados novos materiais. 

de...

Sua relação com a rua é direta, que, por sua vez, é mais do que uma extensão da casa, mas também parte dela (DAMATTA, 2000).

Notamos uma ligação muito forte entre a trajetória pessoal e o arroio, que mais do que um local de residência, marca a identidade das pessoas que ali vivem. Seja pela valorização de um passado idílico, de desbravamento, seja pela depreciação e preconceito que sofrem por morar perto de um "valão", morar às margens do Barnabé significa partilhar uma identidade e uma história. Aqueles que já residiram nas suas porosas margens, viram casas bricoladas serem levadas com a chuva; elas foram reconstruídas e reformadas. Ali recompuseram suas casas e suas vidas em muitas jornadas (ECKERT, 1997; SILVA; ECKERT, 2006).

Boa parte dos moradores vive da coleta e reciclagem de lixo, e outros tantos utilizam sua casa como local de trabalho. O trabalho informal apresentou diversas facetas durante nosso trabalho de campo, destacando-se, sobretudo, o protagonismo feminino. Vimos desde os tradicionais e variados tipos de artesanato até uma consolidada rede de mulheres que colava envelopes para uma gráfica da região, e outra também bem formada rede que preparava resíduos de borracha para reciclagem. Para os homens, o trabalho informal também era representativo. A maioria ocupava seus dias com "bicos" do tipo "faz tudo", atuando como eletricistas, encanadores e em pequenos trabalhos da construção civil. Alguns homens, que estavam desempregados na época de implementação do PAC, conseguiram trabalhar na construção dos edifícios.

Às margens do Arroio Barnabé, nos $5 \mathrm{~km}$ de abrangência do projeto, passando pelos bairros Vila Branca, Parque dos Eucaliptos e Barnabé, o espaço que separa o arroio da rua varia muito. Algumas vezes ele chega a estar a apenas 5 metros do trânsito, e esse espaço é ocupado por pelo menos uma casa. Já na região do "Beco do Mijo", com a maior concentração de casas e densidade populacional por metro quadrado, muitos becos precedem a rua, construindo um denso e diverso labirinto.

Por se tratar de um projeto que focava na extensão das margens do arroio, não havia uma clara identificação com um bairro em particular. De modo geral, morar às margens do arroio significava residir em uma região distante do centro da cidade, distante da avenida que corta essa cidade metropolitana e liga à capital do Estado. Pela ausência de uma malha de transporte público, essa distância dificultava ainda mais o acesso a serviços básicos, pois, postos de saúde, creches e escolas estavam alocados em bairros vizinhos. Apesar dis-

3 Esse beco pode ser considerado o coração do projeto de revitalização do arroio e também o seu calcanhar de Aquiles. Nesse pequeno espaço existem casas muito antigas, cujos moradores mobilizaram-se há muitos anos para regularizar sua situação e declarar o usucapião. A realocação desses moradores é particularmente delicada. 
so, essa região era considerada bem situada, pelas oportunidades de trabalho que oferecia e, sobretudo, quando comparada com outros projetos habitacionais que estavam sendo desenvolvidos na mesma época.

Durante nossa incursão, tivemos a oportunidade de conhecer muitas pessoas e histórias. No entanto, pela nossa posição e trabalho naquele contexto, nossa visão acerca dos residentes do Barnabé foi permeada tanto por nossa visão enquanto consultoras, tanto como pelo papel que esses moradores nos atribuíam enquanto representantes do Estado. Aqui queremos destacar que nossas acepções acerca do Barnabé e de seus moradores são generalizações produzidas num contexto de consultoria e por necessidade de elaboração de um projeto de ação na comunidade. Essa descrição não pode e não tem como objetivo produzir um retrato das pessoas e locais em que vivem, mas sim, contextualizar como nós as apreendemos para nossa prática profissional. Examinemos agora o programa para o qual estávamos trabalhando.

\section{Um programa diferente?}

A linha de financiamento público lançada em 2007 pelo Governo Federal que atende pelo nome de Programa de Aceleração do Crescimento é uma tentativa de inovar a gestão de políticas publicas e criar uma alternativa à tradicional e extensa burocracia. Atribui-se ao PAC o significativo aumento de investimento em obras públicas (de 1,62\% do PIB em 2006 para 3,27\% em 2010) e a criação de um volume recorde de empregos ${ }^{4}$. O PAC apresenta-se, assim, como uma solução imediata e poderosa, sobretudo monetariamente, para combater alguns dos problemas que freariam o crescimento, eminentemente econômico do país. Afim de oferecer a infraestrutura logística, energética, social e urbana necessárias para o desenvolvimento do país, o PAC foi lançado com o orçamento que previa a distribuição de $\mathrm{R} \$ 503,9$ bilhões a serem investidos até $2010 \mathrm{em}$ todo o Brasil.

Parte dessa verba foi destinada ao "Projeto de Revitalização do Arroio Barnabé - Gravataí" - cerca de R\$31 milhões. O PAC Barnabé foi elaborado e pleiteado pela Secretaria Municipal de Captação de Recursos (SMCR) da Prefeitura Municipal de Gravataí ${ }^{5}$ e teve como carro-chefe um projeto arquitetônico de realocação de famílias residentes às margens do Arroio Barnabé. $\mathrm{O}$ aspecto inovador e humanístico de tal projeto residia na possibilidade de realocar tais famílias exatamente na mesma região de sua residência. Com tais características, o PAC Barnabé recebeu o financiamento solicitado, realizou

4 Dados divulgados em http://www.pac.gov.br/sobre-o-pac

5 Nessa época a prefeitura era governada pelo Partido dos Trabalhadores, o mesmo partido que estava à frente do Governo Federal. 

de...

a seleção de um consórcio público para realização da "empreitada global" $\mathrm{e}$ iniciou as obras em fevereiro de 2008.

Divergindo de outros projetos habitacionais que tendem a enviar a população para periferias cada vez mais e mais distantes dos centros urbanos, o PAC Barnabé seduzia a população local e os gestores com essa proposta inovadora. Assim, ao mesmo tempo que a utilização do mesmo território agrada aos moradores e aos financiadores, tal característica, tomada por outro ângulo, causava sério desconforto às próprias famílias e à equipe social por implicar diretamente na remoção, mesmo que temporária, da população de seu local de residência para a construção dos blocos habitacionais.

No projeto apresentado para o financiamento, toda a realocação das famílias foi pensada somente com o uso de casas de aluguel. No entanto, o mercado imobiliário na região não possuía condições de receber essa demanda e a busca por moradias temporárias foi uma grande fonte de dificuldades e entraves. Encontrar casas de aluguel, na faixa de preço financiada pelo programa e seguindo os padrões burocráticos (contratos, comprovantes de residência, recibo de pagamento do aluguel) gerou grandes incertezas e desafios incalculáveis para a equipe social que encontrava-se em meio a um imbróglio de famílias que não querem sair de suas casas; engenheiros apressados para prosseguir suas obras, e uma empreiteira sem casas de aluguel para oferecer.

De fevereiro à maio, o PAC Barnabé foi noticiado intensamente na mídia nacional e local. O principal motivo de efervescência foi a alocação provisória de 8 famílias em contêineres para que seu antigo local de residência fosse usado para a construção dos primeiros blocos habitacionais do PAC. Tais moradias foram caracterizadas como "desumanas" e chamaram atenção de defensores de direitos humanos em toda a região que vieram apoiar a causa dos "contêineres" - como ficaram conhecidos. Nossa contratação se deu em parte pela pressão para melhorar a equipe social após a midiatização dos contêineres. Após certo tempo, esse e outros pleitos foram esquecidos, e desde nossa chegada ao projeto até a entrega dos primeiros blocos, os contêineres continuaram ativos.

\footnotetext{
6 Esse termo determina que a empreiteira será responsável pela gestão completa do projeto: sua parte técnica e sua parte social.

7 Tal disputa pode ser tensionada se observarmos, em perspectiva, o antigo local de residência das famílias residentes nos contêineres, cujos relatos afirmam ter características que poderiam ser interpretadas como "desumanas", tanto quanto as novas habitações. No entanto, as residências em contêineres não pode ser tomada como uma alternativa viável para um projeto do porte do PAC Barnabé. Acrescentam-se aí as inúmeras versões sobre a decisão de tal alojamento. Algumas afirmam que tratou-se da escolha das famílias que desejavam viver juntas, porém não encontravam casas de aluguel nas quais poderiam residir próximas. Outras versões culpabilizam a equipe social por mal administrar as necessidades dos seus beneficiários.
} 


\section{Pra que serve uma equipe social?}

Nossa contratação como consultora e coordenadora da "equipe social" do PAC Barnabé foi consequência de exigências da Caixa Econômica Federal $(\mathrm{CEF})$, instituição fiscalizadora do andamento de tal projeto e responsável pela transferência das remessas de dinheiro à empreiteira. Mensalmente os técnicos da CEF visitavam as obras e recebiam dois relatórios: o "técnico" (leia-se arquitetônico) e o "social". Somente após a aprovação de ambos a verba utilizada para a realização das atividades do mês anterior era repassada à empreiteira.

A distinção, sempre presente, do que fazia parte do "técnico" e dos domínios do "social" é peça chave para compreender as dinâmicas do PAC Barnabé. Grosso modo, podemos afirmar que apesar do "social" ter parcela própria dentro do financiamento, seu trabalho era sempre regido em função da "obra", símbolo da eficácia e do saber técnico. Ao mesmo tempo, a "obra" era um valor eleitoral inegável, muito apreciado pelo universo político. Nesse sentido, o uso do termo "social" para designar o trabalho realizado pela equipe formada por cientistas sociais, psicólogos e assistentes sociais se aproximava do uso corrente da expressão "fazer o social". Uma mescla dos atributos sociais de um "apaziguador" e "bobo da corte".

O caráter secundário e mesmo auxiliar da "equipe social" foi posto em xeque pela equipe da CEF, quando aferiu que a equipe social do PAC Barnabé era deficiente, tanto pelo número de membros, quanto pelo volume de atividades realizadas em cada mês. Os analistas da CEF exigiram que um funcionário público da Prefeitura Municipal de Gravataí, com formação na área de intervenção ou Ciências Sociais, passasse a coordenar a equipe social e que esta fosse ampliada para que o repasse da verba fosse efetuado ${ }^{8}$.

Diante de tal exigência, passamos a ocupar o trabalho de consultora e coordenadora da equipe de trabalho social para elaboração de projeto de intervenção continuada na área de abrangência do projeto. Nessa mesma época, foi contratada uma cientista social com formação técnica em Desenvolvimento Ambiental e Educação para ser responsável pelo projeto de educação ambiental, somando-se à equipe já composta por uma assistente social, uma psicóloga, uma estagiária em tempo integral e um "cartógrafo".

Míriam, a estagiária, era a única funcionária que trabalhava 40 horas semanais. Os outros membros da equipe eram: Edluza, assistente social, que trabalhava no turno da manhã; Janete, psicóloga, trabalhava no turno da tarde;

$8 \quad$ No momento em que iniciamos nosso trabalho, existia uma grande animosidade entre as equipes social e técnica por conta do atraso no repasse das verbas. Esse atraso foi corrigido quando a SMCR acatou as medidas da CEF de ampliar as ações e tamanho da equipe social. 

de...

Luciano, que possuía um curso técnico em cartografia; e, Pistão que, como o codinome anuncia, era o motorista. É importante destacar que Míriam já fazia estágio na prefeitura há algum tempo. Ela e os demais estagiários do setor burocrático da SRMC se conheciam de longa data. Já Edluza e Janete eram novas no setor e tinham outros trabalhos além do que executavam no PAC. Quanto à Juliard, ninguém sabia ao certo o que fazia ali.

\section{Mas, afinal, qual é o trabalho da equipe social?}

Essa pergunta invocada na nossa prática cotidiana, repetida por colegas e até mesmo pela comunidade, precisa ser contextualizada. Existe um ideal do que deve compor o trabalho social dentro de um projeto como o PAC. A CEF, fazendo a análise dos relatórios mensais, buscava contrapor essa expectativa com a prática. Na nossa experiência, o trabalho da equipe social esteve muito ligado às demandas de atendimento, as quais vinham da comunidade, da equipe técnica, da chefia da SMCR e da CEF.

Para que essa prática possa ser melhor descrita, exploraremos situações que fazem parte do nosso emblemático "primeiro dia" de trabalho. O trabalho da equipe social será explorado aqui em duas partes; na primeira delas, traremos um caso que fala da resolução de conflitos e diferentes noções de direitos; na segunda parte, exploraremos a principal atividade da equipe no PAC Barnabé: o trabalho na rua.

\section{Parte I: gestão de direitos}

Visitamos a sede ${ }^{9}$ em distintos momentos e partilhamos o primeiro dia de trabalho. Chegando ao PAC Barnabé, entramos na "sala do social". Era a primeira sala à esquerda. A sala possuía três mesas, um armário e duas portas (uma com acesso direto da recepção, e outra que dava acesso aos outros ambientes que compunham a sede $)^{10}$. Cabe destacar que o fato dessa sala oferecer acesso direto à recepção, mantendo, desse modo, a privacidade do restante da sede, revela uma separação do trabalho "técnico-administrativo" do atendimento à comunidade. A ampla janela que se abria para a frente do edifício estava coberta pela pesada grade e não era aberta com frequência. Ao lado do

\footnotetext{
9 Diferentemente das demais sedes da prefeitura, a SMCR estava próxima da área de abrangência do PAC Barnabé. Essa decisão de criar uma sede mais próxima ao local de atuação visava melhor servir a comunidade uma vez que o deslocamento dessa região até o centro da cidade é deficitário de opções do transporte público.

10 A sede possuía mais duas salas privadas - do arquiteto e do secretário (responsável pela Secretaria de Captação de recursos da Prefeitura de Gravataí), que ficavam ao fundo de uma ampla sala dividida ao meio, sem paredes. No lado direito, ficavam os funcionários do gabinete que respondiam as funções burocráticas; do lado esquerdo, os engenheiros, arquitetos e estagiários. Ao fundo um corredor levava a pequena sala dos motoristas e à cozinha. Havia, ainda, espaço para armários, banheiro e um pequeno almoxarifado.
} 
armário, vários coturnos cobertos de barro demonstravam o trabalho na rua e em locais de obra. Fomos recebidas por Míriam. Alegre, ela começa a nos explicar a dinâmica da sala e do trabalho da equipe. Míriam confessava que a falta de sincronia da equipe lhe causava exaustão, ao colocar a par diariamente os demais membros da equipe dos episódios acontecidos.

Apesar de pequena, a sala era muito frequentada. Passou por nós um rapaz que entrou e saiu sem delongas. Ele foi seguido de uma rápida incursão de Edluza. Ela era bastante espontânea e parecia querida na equipe por suas brincadeiras e bom humor. Ao nos introduzir ao trabalho da equipe, nos apresentou uma agenda, ou melhor, uma agenda para cada turno de trabalho. Nessas agendas, ela e Janete escreviam diariamente o que haviam feito na comunidade. Perguntamos em que consistia o trabalho que estavam desenvolvendo, ao que ela nos respondeu que se tratava da "remoção do Beco do Mijo".

Em meio a essa rápida introdução, fomos avisadas de que havia um casal que esperava para ser atendido. Pelo nome, Edluza e Míriam sabiam do que se tratava. Edluza imediatamente pediu que Míriam fosse se esconder com um enfático "Vai lá pra dentro e não aparece aqui até eles irem [embora]". Ela complementou sua fala ao nos ver um tanto quanto surpresas dizendo: "Porque...vocês sabem [hesita dramaticamente com as mãos sobre a mesa], tiro na cabeça mata". Pedimos para que Edluza explicasse a situação. Ela nos afirmou resumidamente que se tratava de uma "fraude", e que o rapaz era um conhecido "traficante".

O casal entrou na sala. Eles foram convidados a se sentar em duas cadeiras. Edluza, já sem uniforme, se sentou atrás da mesa e começou a falar. A moça se chamava Daniela, grávida de aproximadamente 5 meses. Ele se chamava Cláudio, segurava um capacete em seu colo e olhava firmemente para cada um dos presentes. Daniela segurava sua barriga enquanto que a Edluza e Cláudio discutiam energicamente.

Fora da sala, o secretário da SMCR chegava e anunciava em alta voz, enquanto se dirigia à sua sala: "Fraude, não! Eu não vou tolerar fraude aqui!". Lembro-me que nos perguntávamos como ele sabia, literalmente, ao entrar na sede, que o casal que estava sendo atendido era o já "famoso" casal da suposta "fraude"? Como secretário da SMCR, ele vestia diariamente seu uniforme do PAC Barnabé, composto de camisa, calças, e colete devidamente bordados com o emblema da obra. Distinguindo-se de outros políticos, e principalmente do arquiteto que preferia usar terno e gravata, o Secretário ${ }^{11}$ usa o uniforme. Assim, orgulhoso do projeto, ele passou a ser facilmente reconhecido na comunidade.

11 Apesar de ser um cargo público, preferimos não momear o secretário. Sua identidade fica preservada também pela circulação de pessoas nesse cargo. 

de...

Enquanto isso, Edluza argumentava com o casal e solicitava que Cláudio assumisse seu filho que estava no ventre de Daniela. Em meio à discussão, começávamos a entender que Daniela fora proprietária de uma casa no "Beco do Mijo", segundo ela, construída com muito esforço e às custas de muita economia num espaço que exitia no terreno da casa de sua mãe. Essa casa foi demolida após sua realocação para a construção de um dos blocos habitacionais. Nesse momento, não se questionava a veracidade da existência de sua casa.

O problema é que Cláudio, o namorado e pai do filho que esperava, ofereceu uma casa ao PAC para alugar à Daniela na ocasião de sua realocação provisória. Quando a equipe soube que seu namorado era o locatário de sua casa de aluguel, somada ao fato da gravidez de Daniela se tornar visível, a hipótese de fraude surgiu. Ao tomar conhecimento desse fato, o Secretário, Edluza e parte da comunidade, sobretudo vizinhos que comunicaram a relação entre Daniela e Cláudio ${ }^{12}$, puseram em xeque o direito de Daniela de receber um apartamento do PAC. Para Edluza e o Secretário, toda a situação de Daniela representava uma fraude.

Já na perspectiva de Daniela e Cláudio não existia nenhum impedimento no estabelecimento de uma relação pessoal e um contrato de locação de apartamento com a futura mãe de seu filho. Para eles, o Programa estava pagando aluguel para todos os moradores do Barnabé que haviam sido realocados e tinham tido suas casas demolidas. Ora, por que para Daniela seria diferente? Além disso, Daniela enfatizava que não morava "com" Cláudio, mas morava em uma peça, completamente separada da casa de seu namorado.

Nesse momento, o fato de Daniela ter tido uma casa no Beco do Mijo, área de abrangência do projeto, não é critério suficiente para que seu direito ao apartamento prevaleça. É a relação, ao mesmo tempo pessoal e comercial entre Daniela e Cláudio, que deixa a resolução do problema mais complexa. Em determinado momento, foi discutida a possibilidade de anular o contrato de aluguel, já que a validade dessa relação estava pondo o direito de Daniela ao apartamento na berlinda. Isso estava fora de questão para Daniela, que via essa proposição como abrir mão de um direito, e também estava fora de questão para o Secretário e Edluza que diziam que esse contrato de aluguel era a

\footnotetext{
12

A fofoca é um dos desafios cotidianos no PAC. Fonseca (2004) afirma, a partir dos seus dados de pesquisa realizada junto a grupos populares em Porto Alegre, que a fofoca pode ser um importante aliado para obtenção de legitimação e até mesmo status dentro do grupo. Desse modo, a equipe estava sempre sendo posta a par de novos eventos e informações e acreditava-se que oferecer certas informações poderia auxiliar na obtenção de seus pleitos pessoais. Como exemplo, uma moradora critica a atuação de uma "líder" comunitária, afirmando que ela tem vendido terrenos baldios ao lado da sua casa para pessoas que nunca moraram na vila. Ainda na mesma conversa, emergem os termos de troca pela informação oferecida anteriormente: seu filho, cuja casa teria sido varrida na última chuva, teria "muito mais direito" a receber o apartamento do que esses "novos" moradores, mesmo que esse não mais residisse no seu terreno, pois, ele havia passado toda a sua vida ali.
} 
evidência da intenção de "fraudar" o sistema. Mas como provar que tratava-se de uma fraude?

Muitas informações contraditórias e fortes palavras foram colocadas sobre a mesa para decidir se Daniela teria, ou não, direito ao apartamento. Para além dos critérios de inclusão estabelecidos no Projeto, a prática da análise caso a caso parece criar critérios de exclusão. Como pesar esses critérios? Curiosamente, o fato de Daniela estar grávida de Cláudio parecia ser um importante fator de exclusão. Era ponderado que "se" Cláudio assumisse o bebê, Daniela estaria sob sua proteção e não precisaria mais do Estado, nem do apartamento. Logo, decidir se Daniela tinha ou não direito ao apartamento parecia estar baseado em se Daniela "precisa" ou não do apartamento.

Para além dos critérios de inclusão desse projeto, no atendimento de Daniela e Cláudio existia a exigência de uma tomada de decisão. Mas quem tomaria a decisão final? Nesse caso, o Secretário dizia de sua sala que não seria tolerada fraude nesse projeto. Edluza, que havia trabalhado na realocação de Daniela desde o princípio, se retirou da sala dizendo que "na minha opinião ela [Daniela] não tem direito!". Dentro da sala, Daniela lamentava ter permitido a demolição de sua casa. Enquanto isso, escutávamos repetidas vezes: “Fraude, aqui não!'”. É claro que a preocupação com a fraude é uma preocupação legítima. No contexto de projetos habitacionais, a forma mais comum de fraude é a criação de novas casas, mas o caso de Daniela era outro.

Mas fraude, no vocabulário do PAC Barnabé ia muito além da atenção a casos ambíguos. Fraude ${ }^{13}$ é um termo que aparece para designar ações da comunidade "contra" o Estado. Contrariamente ao proposto por Clastres (2013), na sua concepção da "sociedade contra o Estado", na qual afirma a inexistência e recusa de Estado pelos índios Guayaki, no PAC Barnabé, a poderosa ideia de sociedade contra o Estado, sendo expressa através da retórica da fraude, é marcada pelo uso e manipulação dos instrumentos do Estado para conseguir seus objetivos. Na prática, por fraude entende-se as estratégias da comunidade para conseguir mais apartamentos por família, ou "criar" novos apartamentos. Esse último foi frequente, com a emergência de pequenas casas que aparecem da noite para o dia em pequenos espaços, como "puxadinhos", novas invasões, etc. Nesse momento, a equipe social, em sintonia com o que pregava o Secretário, partia do princípio que a comunidade estaria tentando tirar vantagem do programa, tentando "extorquir" apartamentos e direitos indevidos.

13 Cabe aqui prestarmos referência ao antropólogo Roberto DaMatta(1997) que revelou em seu trabalho o caráter do malandro, que em alguns contextos da sociedade brasileira pode ser valorizado. Entendemos aqui o medo da fraude como uma reação adversa à malandragem, esperada na relação estabelecida entre o Estado (enquanto política pública) e a população. 

de...

Quando falamos em fraude, estamos discutindo noções como "o quê" constitui um direito e "quem" tem direito a ser beneficiado por um programa social como o PAC Barnabé (BOURDIEU, 1989; SANTOS, 2004). A Antropologia do Direito e da Lei muito se dedicou a explorar desde relações da cultura e a resolução de conflitos, passando por um entendimento de direitos como obrigações ou instrumento de regulação social até, finalmente, abordar o direito ocidental como objeto de estudo. Nesta última perspectiva, que nos interessa em particular, existe a ênfase a questões de dominação de classe, que pode ser entendida como uma percepção do direito como dominação (FALKMOORE, 1978). Segundo Schuch,

A questão desafiante a partir da análise de Bourdieu (1989),vem exatamente das interrogações acerca das possibilidades de transformação nesse sistema de poder, uma vez que, segundo o autor, o direito consagra a ordem estabelecida ao consagrar uma visão desta ordem que é a visão do Estado (SCHUCH, 2009, p. 42).

Em meio a esse ordenamento dos beneficiados ou não pelo Programa, existia a poderosa ideia de um Estado ordenador e balizador da sociedade. Ora, se na prática o Estado era representado pelos seus trabalhadores, a moralidade individual da assistente social - que via o casal de namorados sentados do outro lado da mesa como uma unidade indivisível, e estava emitindo um julgamento "certo" e "errado" na forma de "direito" aos apartamentos - era a moralidade do Estado.

Junto com esse ordenamento de direitos, existe uma ética de comportamento esperada daqueles a quem tais direitos foram concedidos. As expectativas da equipe social quanto às determinações de quem tem direito implica forjar uma relação de "fidelidade" entre equipe e beneficiários. No descumprimento dessa relação de fidelidade, emergem conflitos. Esses conflitos vinham do sentimento de que a comunidade não valorizava aquilo que estava recebendo e tratava com "ingratidão" os funcionários do Programa.

Em meio a muitas versões sobre o caso de Daniela, a tomada de decisão sobre seu direito ao apartamento é particularmente delicada. O que viemos a descobrir, durante o tempo em que atuamos no PAC Barnabé, é que cada uma das decisões tomadas marcaria uma chuva de consequências, seja para a comunidade, que passa a elaborar seus critérios, exceções e disputas sobre o que é certo e justo, seja para política, que começa a elaborar os critérios eleitorais, e, ainda, para a equipe que aprende, na prática, que a aplicação de políticas públicas, apesar de seus rígidos critérios, não se aproximava em nada à uma ciência exata. 


\section{Parte II: Trabalhando na rua (mas trabalhando pra quem?)}

A realocação provisória das famílias que residiam no local onde seriam construídos os blocos habitacionais do PAC Barnabé foi atividade que exigiu muitos esforços e ocupou grande parte do tempo da equipe social. Relatos dos demais membros da equipe demonstravam que o processo de realocação provisório foi uma atividade tida como perigosa e, em algumas ocasiões, foi necessário o uso de coerção policial. Temendo pela segurança da equipe social, foi designado para acompanhar as "gurias do social" o cartógrafo Juliard. Esse rapaz foi escolhido para esse trabalho por possuir porte de arma. Na equipe que já estava em atuação, a presença da arma em campo era bem vista, existia um temor bastante consolidado por conta de conflitos e ameaças anteriores.

Nossa descoberta da presença de uma arma no contexto de trabalho de campo, atendimento e intervenção foi bastante peculiar e ocorreu ainda no primeiro dia de trabalho. Havia sido agendada uma reunião na qual seríamos oficialmente apresentadas à equipe e discutiríamos nosso plano de ação. Enquanto aguardávamos a chegada de todos, Débora se sentou em sua "nova" mesa e começou a abrir as gavetas para se instalar. Em uma das gavetas ela teve uma surpresa. Na segunda gaveta havia uma pistola, acessivelmente colocada ao lado de um creme dental e uma escova de dentes. Quando relatava, ainda em choque, que havia uma arma na gaveta, seguiam-se perguntas como "que tipo de arma?". Débora respondia que tratava-se de "uma arma, com balas e que dá tiros". Miriam nos explicou que a arma era uma exigência do Secretário para assegurar a segurança da equipe em campo.

Seria o medo que levou nossas colegas a aceitarem a presença de uma arma em campo? Seria esse o mesmo medo que sentiu Débora quando abriu sua gaveta e viu banalmente colocado ao lado de um creme dental uma arma de fogo? Questionando o fácil acesso à arma - afinal ela estava disponível para qualquer um que por curiosidade ou necessidade abrisse uma das gavetas da mesa - Juliard, o portador da arma, explicou que deixou a arma na gaveta porque ela era muito pesada. Ironicamente, ir a campo, conhecer pessoas, mudar seu cotidiano de forma abrupta parecia mais pesado quando se carrega uma arma nas costas.

Nós recusamos a companhia da arma e isso causou imenso estranhamento entre nossos colegas. Será que ao recusar a companhia da arma, ou a companhia de um capanga e/ou guarda-costas, nós nos colocávamos numa posição vulnerável? Será que havíamos tomado a ideia do risco em campo como ingrediente fundamental do que nós chamávamos de "fazer etnográfico"? (FLEISCHER; BONETTI, 2007; FLEISCHER, 2010). Ora, Leach ou Malinowski jamais adentrariam uma aldeia com uma pistola embainhada! Ou 

de...

seria a arma a tiracolo um item de troca, uma versão dos espelhos e fumo? Seria essa uma troca perversa, em que tacitamente a arma era o "passe" para a intervenção? Poucas respostas e muitas perguntas continuaram a emergir desse episódio que marcou diferenças e, sobretudo, nos legitimou ora em uma posição perigosa, ora em uma posição de perigo.

A recusa da arma nos "armou" ao nos investirmos de certa legitimidade junto à equipe. Nossa "coragem" mostrava que não temíamos a comunidade e, perigosamente, nos investia de ideais "humanitários" que foram mal vistos pela chefia, pois poderíamos confundir o lado para o qual trabalhávamos. Mas afinal, pra qual lado estávamos trabalhando? Essa pergunta remete à questão enunciada por Howard Becker (1967), e retomada por Fassin (2013), quando o último problematiza a etnografia pública e o público da etnografia. A resposta de Becker para essa questão é de sempre estar no lado do subordinado. De certo modo, ao nos engajarmos no projeto estávamos acreditando que ele buscava melhorar a qualidade de vida da população. Diante dessa questão, sem hesitar, nos posicionávamos do lado das pessoas e contra o Estado, apesar da ironia contida aí, já que trabalhar para o Estado era visto como um antônimo de trabalhar para a comunidade. Já na escrita desse artigo, ao tornarmos nosso trabalho público, talvez pelo tempo transcorrido ou amadurecimento profissional, nossa reflexão nos leva à opção de Fassin: a recusa a um posicionamento e a tentativa de traçar essas tensões na atuação e produção de políticas públicas e Estado.

Para Gupta e Ferguson (2002), existem duas percepções bastante difundidas acerca do Estado. Trata-se da compreensão de um Estado vertical, cuja imagem predominante é a de uma torre de marfim, acima e sobre a sociedade; e a de um Estado encompassado, visão segundo a qual o Estado está fundido com a nação e é representado em círculos que se ampliam desde a família até sua versão mais generalizante. No imaginário da equipe social, o Estado estava inacessível à comunidade; dessa forma, qualquer comunicação poderia reverberar em uma mudança "de lado", como se Estado e comunidade fossem rivais. No entanto, na prática, a ideia de um Estado vertical não é tão evidente. Gupta e Ferguson argumentam que os estudos do Estado devem explorar a relação entre Estado, espaço e escala. Essa relação, intimamente ligada entre estado e a comunidade local, ajuda a entender como são produzidas e mantidas algumas hierarquias.

$\mathrm{Na}$ rivalidade entre Estado e comunidade, expressa pela chefia do PAC Barnabé, existia mais do que uma determinada percepção de Estado, mas uma profícua revelação acerca das artes de governar. A governamentalidade foi um tema bastante aprofundado por Foucault (1991). O autor busca as origens da preocupação com a governamentalidade no século XVI, quando filósofos e legisladores buscavam formas de optimizar o bem-estar da população. $\mathrm{O}$ 
bem-estar da população estaria ligado tanto aos homens quanto à coisas, e diz respeito a temas como fertilidade, reprodução, fome, morte, território, acidentes e epidemias (só para citar alguns). A arte de governar, portanto, diz respeito a quando e como intervir nessas situações.

Durante nossa atuação, ingênuas e/ou inexperientes, acreditávamos que esse projeto poderia mudar a vida daquelas pessoas para melhor; que, se bem aplicado, aqueles recursos seriam mais do que bem vindos. A tensão entre Estado e comunidade na nossa prática de trabalho nos colocou em uma posição desafiadora. Ao recusarmos a arma a tiracolo e decidirmos ouvir as demandas da comunidade, rompendo com a política de desconfiança que pairava no ar, estávamos indo contra a SMCR, contra o Estado. Essa posição de enfrentamento é o que Bonetti e Fleischer (2007) chamam de assumir a prática e sentidos de ação do pesquisador para além do mito romantizado do "antropólogo-herói”, problematizando a relação risco-desafio/risco-ameaça.

Diante dessas tensões, na próxima parte do artigo buscaremos situar desafios do trabalho de cientistas sociais e antropólogos em negociação com saberes "técnicos" das ciências exatas que supõem ter um conhecimento alheio às relações humanas para a implementação de políticas públicas como o PAC Barnabé.

\section{"De social, todo mundo entente um pouco": a estrutura física e social e a especificidade do trabalho de cientistas sociais.}

Um dos grandes obstáculos ao trabalho de cientistas sociais nos setores de intervenção e políticas públicas é a negociação de sua expertise. No caso do PAC Barnabé, um projeto habitacional, a necessidade de uma equipe especializada no atendimento social foi secundária, até tornar-se uma exigência da CEF para o repasse da verba. Não se reconhecia a especificidade desse "trabalho social" e, quando inserido nesse contexto, o próprio profissional vai se sentir pressionado a decidir de que "lado" se encontra, conforme anteriormente explorado.

A ambiguidade do papel de cientistas sociais, especialmente de antropólogos, nas políticas públicas foi tema de reflexões originais em diferentes contextos de pesquisa (BONETTI, 2001; KNAUTH, 1998; PAIM, 2000, 2006). Um dos principais aspectos mencionados por essas autoras é a percepção de que existe um claro descompasso entre dois universos, e os antropólogos são chamados para facilitar esse processo. No PAC Barnabé, nossa principal função era validar o projeto social junto aos financiadores (CEF) e facilitar o trabalho da equipe técnica, "domando" a comunidade, ou tirando-a do caminho nas práticas de realocação. 

de...

$\mathrm{Na}$ época de realocação das famílias que residiam na Av. Barnabé, onde seria construída uma avenida, a equipe de engenheiros foi supervisionar a demolição das casas. Muitos moradores ainda se encontravam na Avenida esperando por suas casas de aluguel, cujo processo de locação era muito lento. Quando a patrola demoliu uma das casas que havia sido desocupada, esse pesado maquinário rompeu, por acidente, os improvisados canos que faziam a alimentação de água da região. Os remanescentes membros da comunidade exigiram que o engenheiro responsável pela demolição consertasse o feito. Esse engenheiro, um senhor de aproximadamente 55 anos, cabelos brancos, que impunha um grande impacto nos ambientes por ser muito alto, respondeu à comunidade dizendo que não se tratava de um problema seu. Seu "pouco caso" provocou revolta e ele precisou retirar-se da Av. Barnabé às pressas e sob escolta da patrola que havia feito a demolição. Na sede do PAC Barnabé, ainda nervoso com o ocorrido, o engenheiro tomava chá e chamava pelas "gurias" do social dizendo que não iria mais sozinho à vila. Após esse episódio, tornou-se mandatório que algum membro da equipe social acompanhasse a demolição junto com os engenheiros para "acalmar os ânimos" da comunidade.

Vimos uma mudança no papel dos membros da equipe social, que no início dos trabalhos estavam sujeitos à proteção e precisavam ser escoltados por um homem armado em campo, para a de "asseguradores" do bem-estar da equipe técnica frente à, cada vez mais "perigosa", comunidade. Essa perspectiva converge com o que Knauth (1998) caracterizou como uma visão muito reducionista do lugar e função do antropólogo. Segundo a autora, o antropólogo é visto como um mero tradutor, alguém que pode identificar empecilhos e resolvê-los. Até a identificação de empecilhos, poderíamos estar na mesma página que nossos colegas de trabalho, porém, na sua resolução encontrávamos dificuldades maiores.

Um dos principais focos do nosso trabalho foi a modificação do projeto arquitetônico que não atendia às necessidades e a pluralidade da comunidade. Não é de se espantar que o estilo de vida e necessidades da comunidade eram entendidos como muito mais maleáveis do que o desenho de uma planta baixa. Nessa negociação estávamos oficialmente trabalhando contra o Estado, representado, nessa antinomia, pela equipe técnica que tinha como prioridade respeitar prazos e orçamentos.

No projeto arquitetônico do PAC Barnabé muitas mudanças são propostas para o cotidiano da comunidade. A começar pela passagem de casa para apartamento, o que implica na convivência com a rigidez de paredes feitas a partir de blocos cerâmicos. Essa referência não se trata de uma simples anedota quanto à plasticidade dos materiais utilizados na construção das casas às margens do arroio. Essa rigidez advém da escolha do material de construção 
dos apartamentos. Os blocos cerâmicos são um material mais econômico e rápido de construção. Isso implica a utilização de blocos de alvenaria no lugar das tradicionais vigas, impossibilitando modificações na estrutura interna dos apartamentos. Todas as paredes divisórias dos apartamentos são as estruturas do edifício, tornando arriscada e comprometedora qualquer mudança.

Os beneficiários do projeto, sem consulta prévia, eram radicalmente retirados de inúmeros aspectos que compunham não somente seu cotidiano, mas também a sua organização social em troca de infraestrutura. Muito além do direito dos cidadãos de terem sido ouvidos no processo de elaboração de suas novas moradias, cabe questionar a viabilidade de tal adaptação, pois, parte de sua socialidade advém da ligação entre casa, rua e vizinhança.

Cabe notar que a vida em apartamentos faz parte de uma construção ocidental, proveniente das classes médias, para as quais morar em um apartamento significa partilhar valores e aspirações da "civilização" contemporânea. Esse ideal é radical e idealmente oposto à "precariedade" das moradias da região. Desse modo, a equipe técnica tomava como ingratidão e ignorância o fato da população "reclamar" de qualquer aspecto do projeto de infraestrutura.

Um dos moradores, curiosamente, veio até a sede para falar com um engenheiro. Inesperadamente, ele foi encaminhado à equipe social, já que essa equipe faz o atendimento da comunidade. Sua questão era pertinente. Como era encanador, perguntava-se sobre a forma de escoamento dos banheiros. Míriam o havia recebido e procurou a equipe técnica para que respondessem ao futuro morador. Não acostumados a falar com a comunidade, outro estagiário perguntou ao arquiteto chefe se ele "poderia" responder a pergunta. $\mathrm{O}$ arquiteto chefe viu com maus olhos esse tipo de questionamento de sua expertise. Sua conversa com o rapaz teve como objetivo evitar outros questionamentos do mesmo tipo. Mais tarde, soubemos que a razão desse questionamento era a comparação entre o projeto do PAC e um outro loteamento ${ }^{14}$, no qual sua família também estava inscrita. Sabendo que deveria escolher um dos dois projetos, o rapaz buscou informar-se melhor sobre qual projeto atenderia suas necessidades. Ele optou pelo loteamento.

Em meio a essa racionalização do processo de aplicação de uma política pública, cuja ênfase é posta no "dar" e "receber", a consulta da população para o conhecimento de seus desejos e aspirações foi descartada pela equipe técnica e também pela política. Ao mesmo tempo, foi atribuída à equipe social o papel de "convencer" a população do que "é melhor pra eles". Vários estudos vêm destacando que o "pobre" - entendido aqui como desprovido de recursos 

de...

econômicos, educação e status social - é visto como incapaz de decidir o que é melhor para si mesmo, precisando, assim, de um intermediário, que irá executar sobre ele um poder tutelar (VIANNA, 1999). Neste caso, a equipe social.

Apesar de nossa formação enquanto cientistas sociais e antropólogos estar ainda majoritariamente voltada para a prática acadêmica, nossa atuação - cada vez mais frequente nesses contextos - tem sinalizado que nossa especialização, treinamento e experiências de pesquisa nos auxiliam a captar e destacar aspectos importantes da organização social da comunidade, indispensáveis à melhor aproximação do projeto com a comunidade. No entanto, devido à rígida separação das atribuições de cada equipe, a equipe social não possuía o status nem o domínio do conhecimento julgado necessário para "opinar" quanto às mudanças relevantes para melhor acomodar a necessidade da comunidade junto ao projeto arquitetônico ${ }^{15}$.

Uma das tentativas de comunicação entre equipes revela, de forma exemplar, éticas e sensibilidades incompatíveis na execução da política pública. $\mathrm{Na}$ pequena área de serviço dos apartamentos, a janela foi desenhada como uma basculante, não permitindo o acesso aos trilhos para estender roupas lavadas. Em meio à indecisão sobre o que fazer, a equipe técnica consultou a equipe social. Nós afirmamos que não havia dúvidas quanto à necessidade de trocar as basculantes para uma janela que permitisse o acesso aos trilhos. Essa possibilidade foi descartada pelo longo tempo de espera e questões orçamentárias. Para resolver o problema a equipe técnica projetou varais coletivos, mas essa alternativa não foi unânime, pois essa solução não soava boa pelo risco de furto e pela falta de espaço para todas as famílias estenderem suas roupas principalmente em tempos invernais quando chove muito e todos aproveitam um dia de sol para colocar a roupa suja em dia.

Diante desses argumentos, os jovens engenheiros e arquitetos, alguns ainda estudantes, descobriram a solução para o problema dos furtos: as mulheres que segundo eles "não sabem fazer nada que não seja tomar chimarrão na frente da casa o dia inteiro, que levem a sua cuia pra baixo do varal". Seguido de muitos risos e suspiros dos membros da equipe social, ainda houve tempo para que argumentássemos que entre um chimarrão e outro muita coisa pode ser feita se estamos "em casa", lembrando dos outros trabalhos executados por essas mulheres que estão longe de "não fazer nada". Apesar desse esforço de contextualização, uma colega engenheira emitiu sua opinião e acabou com qualquer argumentação plausível, dizendo que não seria preciso se preocupar, pois haverá espaço para todas as famílias uma vez que "agora eles vão ver o que é bom...pagando a conta de água, eles vão aprender a lavar roupa!" 
Alguns dos trabalhos informais, mais comuns entre as mulheres que viviam no Barnabé é justamente "lavar roupa pra fora" ${ }^{\text {. }}$. No processo de adaptação à vida em apartamento, nossa colega afirmava que a comunidade iria a aprender a lavar roupa, sem situar a composição familiar e fonte de renda que ajudavam a preencher os varais que produziam tanto estranhamento. Em meio à acalorada discussão que se seguiu, chegamos à conclusão que não estávamos tentando debater a alternativa que melhor atendesse as necessidades da comunidade, mas sim como essas necessidades deveriam se adaptar. Assim, em nome de impedimentos burocráticos, orçamentários e da falta de disponibilidade da equipe técnica, toda a adaptação sempre viria da comunidade e não da estrutura rígida dos apartamentos e suas estreitas aberturas.

Nosso trabalho, assim, não necessitava de nosso conhecimento, nem de nossa expertise. As informações que possuíamos sobre a comunidade, formas de geração de renda e necessidades não iriam influenciar a decisão se varais eram realmente necessários ou quais condições seriam otimizadas para sua colocação. O comentário jocoso de nossa colega, ironizando a futura fatura de água, era tão ou mais pertinente que nossos dados, afinal, "de social todo mundo entende um pouco".

A partir de nossa inserção na comunidade constatamos que não só a vida em apartamento desagradava à maioria da população, mas também preocupava pela ausência de espaço para o trabalho que não poderia ser contornada por algumas famílias. Havia ainda uma importante parcela da população cuja única fonte de renda vinha de uma atividade comprometida pela vida em apartamento. Para essas e outras famílias, o projeto inicial e utópico do PAC Barnabé previa a criação de uma alternativa de trabalho - fonte de renda para a população. Essa alternativa deveria ser realizada a partir do investimento em formação e cooperativas comunitárias ${ }^{17}$.

O projeto de geração de renda e investimento em qualificação profissional é uma necessidade de grande parte das comunidades carentes em todo o Brasil. No entanto, essas atividades ganham força quando bem-vindas pela comunidade, enquanto uma empreitada coletiva (ACHUTTI, 1997; PAIM, 2006). Esse não foi o caso do PAC Barnabé. Os moradores mais prejudicados com a mudança para os apartamentos seriam os carroceiros. Essas pessoas não estavam necessariamente à procura de uma profissão e fonte de renda, pois

\footnotetext{
16 Essa modalidade de trabalho que parece estar cada vez mais em desuso ainda era uma alternativa viável de geração de renda no Barnabé. Algumas das mulheres lavavam roupas e materiais para pequenas empresas da região lavando principalmente uniformes que continham sujeira pesada.

17 Encontramos várias dificuldades nas diversas tentativas de unificar os moradores para a criação de um galpão ou estrutura para que pudessem guardar os cavalos e material coletado. Essa possibilidade não vingou, pois os coletores trabalham hoje em forte competição e residem ao longo da extensão do projeto, não se constituindo enquanto "comunidade".
} 

de...

essa profissão, ainda que estigmatizada, lhes proporciona uma renda mensal superior à grande parte da comunidade. É preciso reconhecer que essa foi uma alternativa de renda elaborada e conquistada com muito trabalho e, desse modo, fazê-los abdicar dessa fonte de renda, por algum paliativo não era uma alternativa viável ${ }^{18}$. Face à essa situação, começamos a questionar a possibilidade de criação de um bloco horizontal para realocar tais famílias. A resposta inicial foi rigorosamente contrária. Acreditava-se que o trabalho social poderia simplesmente convencer a população a mudar de "opinião" e "criar" novos empregos.

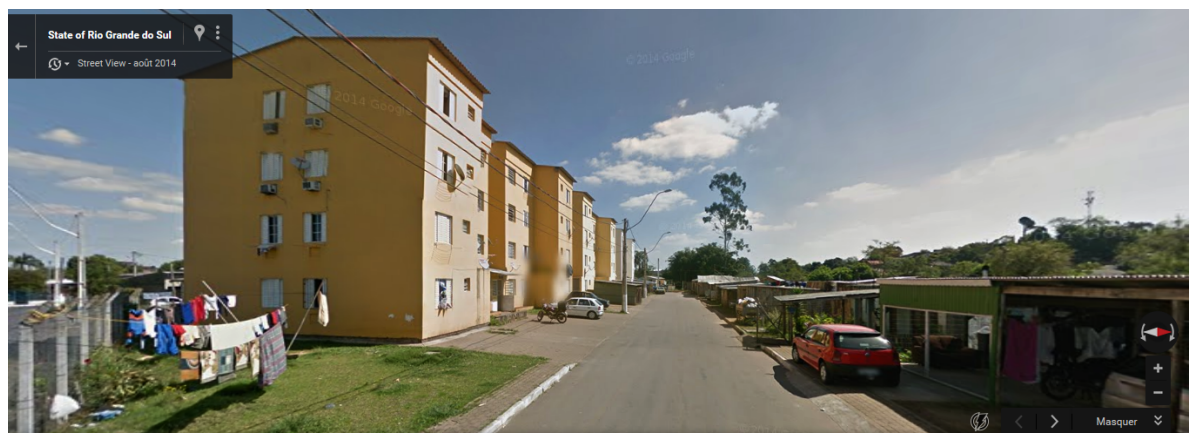

Fonte : Google Maps, $2014^{19}$

No momento em que finalizamos esse artigo (2015), as obras do PAC Barnabé continuavam ativas ${ }^{20}$, mas podemos ver na imagem acima que suas marcas foram deixadas no território, ainda que o projeto não tenha sido concluído na sua totalidade.

Em um intrigante texto, no qual atualiza a questão levantada por Scott (1998), Li retoma a pergunta de por que certas inciativas para melhorar as condições humanas falharam. Para responder essa questão, a autora nos oferece pistas acerca de como a ação de planejamento e execução requer expertises:

A prática posiciona pessoas como sujeitos de variadas capacidades de ação e crítica. No entanto, a prática de planejamento e posicionamento de pessoas como especialistas ou alvo de especialistas; a prática de mapear, realizar um censo e construir uma lei posiciona pessoas, como residentes de uma certa

18 Cursos de formação profissional para pessoas com baixa ou nenhuma escolaridade acabam se tornando paliativos. Durante a nossa "gestão", organizamos cursos de formação de cabeleireiras, manicures e eletricistas. Os dois primeiros foram um sucesso de participação, mas sem grande efeito na geração de renda. Os último não atraiu muitas atenções e no entanto formou solidamente alguns estudantes que tentaram empreender a profissão.

19 Para ver a imagem siga o link : https:/www.google.com.br/maps/@-29.9277116,-51.0482575,3a,65.4y, 18 0h,88.08t/data=!3m7! 1e1!3m5!1sA4kSrBDvWu0MNnBMryw4WA!2e0!6s\%2F\%2Fgeo2.ggpht.com\%2Fcbk\%3Fpanoi$\mathrm{d} \% 3 \mathrm{DA} 4 \mathrm{kSrBDvWu} 0 \mathrm{MNnBMryw} 4 \mathrm{WA} \% 26$ output $\% 3 D$ thumbnail\%26cb_client $\% 3 D$ maps_sv.tactile.gps\%26thumb\%3D2\%26w\%3D100\%26h\%3D80\%26yaw\%3D125.55994\%26pitch\%3D0!7i13312!8i6656

20 Segundo dados do Governo Federal, o PAC Barnabé continua ativo: http://www.pac.gov.br/obra/25254 
localidade, como detentores de direitos e membros de grupos; práticas de parentesco e compadrio colocam as pessoas em hierarquias de gênero e geração; práticas culturais marcam barreiras territoriais e étnicas. Resistência emerge de dentro dessas matrizes e responde a múltiplos campos de poder. (LI, 2005, p. 285 tradução das autoras)

Nesse sentido, nossa reflexão a respeito das dificuldades e impasses no trabalho no PAC-Barnabé corrobora essa afirmação de Li. Estamos de acordo com a autora quando afirma que a prática reforça a capacidade de ação. Essa perspectiva deve ser considerada tanto para a ação da comunidade, quanto para refletirmos acerca do nosso campo de atuação na aplicação de políticas públicas.

\section{Reflexões finais}

O Arroio Barnabé e seus moradores estavam literalmente às margens da sociedade. De longe, eles eram um só e representavam todo o desgaste da ausência de Estado e de uma economia volátil. Contrariamente ao senso comum, a grande maioria dos habitantes das margens do Arroio Barnabé são trabalhadores. A partir das inúmeras adversidades e dificuldades, comuns às camadas menos abastadas da população, a comunidade do Barnabé trabalha. E, como afirma uma das mais antigas residentes da região, Dona Margarida: "Aqui a gente trabalha de dia pra comer de noite, e assim vai...". No entanto, aos olhos dos técnicos que aplicavam uma política pública, essa intensa lógica de trabalho não era facilmente perceptível. Os cinco quilômetros de extensão do projeto atravessavam vários bairros e comunidades heterogêneas, cujo jogo de legitimação pelo "direito" a "ter direito" a um apartamento estava produzindo disputas, fofocas e estigmatização, transformando vizinhos em categorias distintas de humanos (RIBEIRO, 2004).

No exercício de nossas atividades, como coordenadora e consultora dessa política pública, nossa atuação foi questionada pela escolha de um lado: o do Estado, ou o da comunidade. Nossa perspectiva de trabalho - tentando levar em conta a especificidade dos residentes do Barnabé e a tentativa de situá-los frente ao direito à moradia, buscando mais do que um "teto", mas uma moradia que atendesse suas necessidades - foi entendido como trabalhar "contra o Estado". Se o universo das políticas públicas, ainda que utopicamente poderia ser pensado como um grande esquema para melhorar a condição humana (LI, 2005), a experiência do PAC Barnabé revela que pressa e improvisação são dois elementos que não devem coincidir num mesmo universo de atuação.

$\mathrm{Na}$ lógica de implementação PAC Barnabé, enquanto uma política pública, os moradores da região não poderiam influenciar a "obra", e qualquer exigência que essa população tivesse poderia ser interpretada como ingratidão, diante 

de...

do esforço de colocar tal obra em funcionamento. Não se trata de uma simples pessoalização de um serviço público, mas do fato de que a maioria das pessoas que trabalhavam nesse projeto, tanto da equipe social como técnica, acreditavam que estavam mudando qualitativamente a vida dos moradores do Barnabé.

No entanto, a busca por "uma vida melhor" significava o abandono completo da vida que possuíam anteriormente. Não se tratava de um projeto de continuidade, como apregoava a projeto financiado, cujo carro chefe era justamente a continuidade da vida comunitária, mantendo as famílias na mesma região, e não realocando em bairros periféricos como faz a maioria dos projetos habitacionais. Provavelmente, a maior falha do PAC Barnabé, e da nossa participação nesse projeto, tenha sido a de não conseguir comunicar a importância da participação da comunidade na escolha das prioridades para sua moradia. Por essa razão, para que projetos de investimento massivo e em curto prazo como esse possam ser implementados eles devem ser introduzidos em locais e contextos nos quais já exista um debate e projeto junto à comunidade.

Acreditamos que a dificuldade de efetivamente executar um trabalho social vem de quatro fatores: 1) da dificuldade de antropólogos e cientistas sociais em construir um lugar legítimo de fala para nossa expertise; 2) como consequência do primeiro, a dificuldade de trabalho e planejamento conjunto das equipes técnica e social; 3) do tempo da política que apressava o projeto social e as obras; 4) finalmente, a falta de agência da comunidade nos processos decisórios.

Desse modo, para um melhor entendimento da relação entre ética, política e conhecimento (VON SCHNITZLER, 2014), precisamos construir uma plataforma que coloque os atores que compõem o conjunto da política pública em uma arena que permita vozes dissonantes na composição do cenário de decisões. Passa pela edificação do direito à moradia, em fazer parte do processo de sua construção, expondo suas práticas cotidianas, suas necessidades e carências. Entendemos que o lugar do cientista social e do antropólogo na aplicação de políticas públicas deve ser consolidado a partir do planejamento responsável das ações sociais, levando em consideração e valorizando as diferentes formas de produção desses conhecimentos.

\section{Referências}

ACHUTTI, Luiz Eduardo Robinson. Fotoetnografia Um estudo de Antropologia visual sobre cotidiano, lixo e trabalho. Porto Alegre: Tomo Editorial, 1997.

BONETTI, Aline. Novas Configurações: direitos humanos das mulheres, feminismo e participação política entre mulheres de grupos populares porto-alegrenses. In: LIMA, ROBERTO KANT DE (Org.). Antropologia e Direitos Humanos. Prêmio ABA/Fundação FORD. Niteroi: Editora da UFF, 2001. p. 137-201. 
BOURDIEU, Pierre. O Poder Simbólico. Rio de Janeiro: Bertrand Brasil, 1989.

CLASTRES, Pierre. A Sociedade Contra o Estado. São Paulo: Cosac \& Naify, 2013.

DAMATTA, Roberto. A casa e a rua: espaço, cidadania, mulher e morte no Brasil. 6. ed. Rio de Janeiro: Rocco, 2000.

. Carnavais malandros e herois Para uma sociologia do dilema brasileiro. Rio de Janeiro: Rocco, 1997.

ECKERT, Cornélia. Questões em torno do uso de relatos e narrativas biográficas na experiência etnográfica. Revista Humanas, v. 1/2, n. 19, p. 21-44, 1997.

FALK-MOORE, Sally. Law as process: an anthropological approach. London: Routledge, 1978.

FASSIN, Didier. WHY ETHNOGRAPHY MATTERS: On Anthropology and Its Publics. Cultural Anthropology, v. 28, n. 4, p. 621-646, 17 nov. 2013. Disponível em: <http://doi.wiley. com/10.1111/cuan.12030>. Acesso em: 30 jul. 2014.

FLEISCHER, Soraya Resende. Hematomas, terçados e riscos. Teoria \& Pesquisa, v. 19, n. 1, p. 91-110, 2010. Disponível em: <http://www.teoriaepesquisa.ufscar.br/index.php/tp/article/ viewFile/209/161> Acesso em: 30 jul. 2014.

FLEISCHER, Soraya Resende; BONETTI, Alinne. Etnografia Arriscada: Dos limites entre vicissitudes e "riscos" no fazer etnográfico contemporâneo. Teoria \& Pesquisa, v. 19, n. 1, p. 7-17, 2007. Disponível em: <http://www.teoriaepesquisa.ufscar.br/index.php/tp/issue/view/67/ showToc $>$ Acesso em: 30 jul. 2014..

FONSECA, Claudia. Família, Fofoca e Honra. Etnografia de relações de gênero e violência em grupos populares. Porto Alegre: Editora da UFRGS, 2004. 245p.

FOUCAULT, Michel. Governmentality. In: G. BURCHELL, C. GORDON, AND P. MILLER (Org.). In The Foucault Effect: Studies in Governmentality. Chicago: Chicago University Press, 1991. p. 87-104.

GUPTA, Akhil; FERGUSON, James. Spatialising states: towards an ethnography of neoliberal governmentality. American Ethnologist, v. 29, n. 4, p. 981-1002, 2002 Acesso em: 30 jul. 2014..

KNAUTH, Daniela. Da rua para casa ou do politicamente correto ao tecnicamente eficaz: A prevenção da Aids entre mulheres. In REUNIÃO ANUAL DA ASSOCIAÇÃO BRASILEIRA DE ANTROPOLOGIA, 21, 1998, Vitória. Anais ...Vitória, ES, 1998.

LI, Tania Murray. Beyond "the State" and Failed Schemes. American Anthropologist, v. 107, n. 3, p. 383-394, 2005. Disponível em: $<$ http://doi.wiley.com/10.1525/aa.2005.107.3.383> Acesso em: 30 jul. 2014.

PAIM, Heloísa Helena Salvatti. O papel do antropólogo junto a instituições de intervenção: civilizar civilizadores? In REUNIÃO DA ASSOCIAÇÃ̃O BRASILEIRA DE ANTROPOLOGIA, 22, 2000, Brasília, DF. Anais...Brasília, DF, ABA, 2000. 
ALLEBRANDT, Débora, FELIX, Tânia M. Entre o técnico, o político e o social: impasses e poderes de...

Técnicos e usuários em programas de assistência social: encontros e desencontros. $A n$ tropolitica, v. 2, n. 21, p. 127-150, 2006.

RIBEIRO, Gustavo Lins. Cultura, Direitos Humanos e Poder. Mais além do império e dos humanos direitos. Por um universalismo heteroglóssico. In: FONSECA, CLAUDIA; TERTO JR, VERIANO; ALVES, CALEB FARIA (Org.). . Antropologia, diversidade e direitos humanos. Dialogos interdisciplinares. Porto Alegre: Editora da UFRGS, 2004. p. 29-51.

SANTOS, Boaventura de Sousa. Vers un nouveau sens commun juridique : droit, science et politique dans la transition paradigmatique. Paris: LGDJ, 2004.

SCHUCH, Patrice. Práticas de justiça: Antropologia dos modos de governo da infância e juventude no contexto pós-ECA. Porto Alegre: Editora da UFRGS, 2009.

SILVA, Roberto Antonio Capiotti da; ECKERT, Cornelia. Cotidianos irregulares? Estudo antropológico da experiência de regularização fundiária junto aos moradores da Vila Batista Flores em Porto Alegre (RS). Iluminuras, v. 7, n. 15, p. 1-36, 2006.

VIANNA, Adriana. O mal que se adivinha: policia e menoridade no Rio de Janeiro, 19101920. Disponível em: <http://laced.etc.br/site/acervo/livros/o-mal-que-se-adivinha/>. Acesso em: 2 fev. 2015.

VON SCHNITZLER, Antina. Performing dignity: Human rights, citizenship, and the techno -politics of law in South Africa. American Ethnologist, v. 41, n. 2, p. 336-350, 2014. Disponível em: <http://doi.wiley.com/10.1111/amet.12079> Acesso em: 2 fev. 2015.

Submissão em: 10/02/2015

Revisão em: 25/08/2016

Aceite em: 09/03/2016

Débora Allebrandt é professora do Prorgrama de Pós-Graduação em Antropologia Social da Universidade Federal de Alagoas, possui graduação em Ciências Sociais pela Universidade Federal do Rio Grande do Sul (2005), Mestrado em Antropologia Social pela Universidade Federal do Rio Grande do Sul (2008) e Doutorado em Antropologia - Université de Montréal (2013). Endereço para correspondência: Instituto de Ciências Sociais, Universidade Federal de Alagoas (Programa de Pós-Graduação em Antropologia Social) Campus A.C. Simões, Av. Lourival Melo Mota, s/n, Tabuleiro dos Martins, CEP:57072-900, Maceió - AL E-mail: debora.allebrandt@ics.ufal.br

Tânia Moreira Felix é graduada em Ciências Sociais pela UFRGS. Trabalhou na elaboração e aplicação de políticas públicas para crianças em situação de rua em Porto Alegre.Atualmente trabalha na Emater - RS, atuando na Secretaria de Desenvolvimento rural, pesca e cooperativismo - na qual assessora a elaboração de políticas públicas para pescadores artesanais. E-mail: taniafelix@gmail.com 